\title{
Chemical and Biological Evaluation of the Aqueous Extract of Peumus boldus Molina (Monimiaceae) Leaves
}

\author{
Bruna Yuka Koide da Silva', Aniele da Silva Neves Lopes', Paulo José Sousa Maia², Josiana Moreira Mar, \\ Laiane Souza da Silva ${ }^{4}$, Edgar Aparecido Sanches ${ }^{5}$, Geone Maia Corrêa ${ }^{1}$, Jaqueline de Araújo Bezerra ${ }^{3}$, Domi- \\ nique Fernandes de Moura do Carmo ${ }^{1, *}$
}

\section{Bruna Yuka Koide da Silva', Aniele da Silva Neves Lopes', Paulo José Sousa Maia², Josiana Moreira Mar ${ }^{3}$, Laiane Souza da Silva ${ }^{4}$, Edgar Aparecido Sanches 5 , Geone Maia Corrêa ${ }^{1}$, Jaqueline de Araújo Bezerra ${ }^{3}$, Dominique Fernandes de Moura do Carmo ${ }^{1, *}$}

'Instituto de Ciências Exatas e tecnologia, Universidade Federal do Amazonas, Itacoatiara-AM, BRAZIL.

2Instituto Multidisciplinar de Química - Centro Multidisciplinar UFRJ Macaé, Universidade Federal of Rio de Janeiro, Macaé-RJ, BRAZIL.

${ }^{3}$ Instituto Federal de Educação, Ciência e Tecnologia do Amazonas - (IFAM), Centro, Manaus-AM, BRAZIL.

${ }^{4}$ Instituto de Química, Universidade Federal do Rio Grande do Sul, Agronomia, Porto Alegre-RS, BRAZIL.

${ }^{5}$ Departamento de Física, Instituto de Ciências Exatas, Universidade Federal do Amazonas, Coroado, Manaus-AM, BRAZIL.

\section{Correspondence}

Dr. Dominique Fernandes de Moura do Carmo

Instituto de Ciências Exatas e tecnologia, Universidade Federal do Amazonas, 69103-128, Itacoatiara-AM, BRAZIL. Email id: dominiquefmc@ufam.edu.br

\section{History}

- Submission Date: 19-09-2021;

- Review completed: 22-10-2021;

- Accepted Date: 01-12-2021

DOI : 10.5530/pres.14.1.8

Article Available online

http://www.phcogres.com

\section{Copyright}

(C) 2022 Phcog.Net. This is an openaccess article distributed under the terms of the Creative Commons Attribution 4.0 International license.

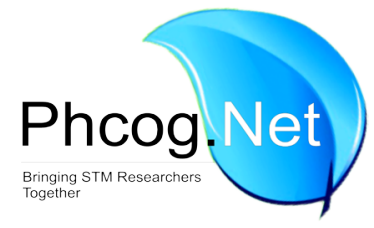

\begin{abstract}
Background: Traditional medicine has inspired the scientific community to discover natural compounds with the ability to inhibit the enzyme acetylcholinesterase (AChE) and with significant antioxidant capacity. These themes are associated with therapeutic processes to decrease the symptoms of Alzheimer's disease (AD). Acetylcholine (Ach) is an important neurotransmitter in the central nervous system responsible for transmitting the nervous impulse and increasing intestinal motility and dilation of sphincters in the gastrointestinal tract. As the species Peumus boldus Molina is widely known and used in folk medicine to treat gastrointestinal discomfort, its constituents could have an affinity for AChE and could be used to treat AD. Materials and Methods: This study evaluated the chemical, inhibitory activity of AChE (using the Elmann method and in silico), antioxidant capacity (DPPH, ABTS, FRAP, and oxidation inhibition of the $\beta$-carotene/linoleic acid system), and quantification of total leaf phenols from a commercial sample of $P$. boldus. Results: The mass spectral analysis allowed identification of the alkaloids isoboldine, boldine, clocaurine, laurotetanine, $\mathrm{N}$-methylurotetanine, reticuline, and $\mathrm{N}$-methylcoclaurine. In the in silico prediction test, the alkaloid $\mathrm{N}$-metillaurotetanine was the best acetylcholinesterase enzyme inhibitor, with energy of $-10.1 \mathrm{kcal} \mathrm{mol}^{-1}$. Conclusion: These results are of scientific relevance for the discovery of new drugs to treat dementia associated with Alzheimer's disease and stimulate the continuity of chemical and biological studies (anticholinesterase and antioxidant action) of prepurified fractions and substances isolated from $P$. boldus leaves.
\end{abstract}

Key words: Boldo, Acetylcholinesterase, Antioxidant activity, Acetylcholine, Alzheimer.

\section{INTRODUCTION}

Alzheimer's disease (AD) is a neurodegenerative pathology characterized by cognitive decline and mental degeneration, with massive and progressive loss of neurons in different regions of the brain. In 2015, approximately 46.8 million people were diagnosed with $\mathrm{AD}$, and by 2050 this number could reach 131.5 million therefore, new approaches are needed for its treatment. ${ }^{[1-3]}$

Since the discovery of the disease, researchers have recognized that its symptoms may be associated with the development of neuritic (senile) plaques, by the extracellular deposit of $\beta$-amyloid (A $\beta$ ) protein aggregates, and by neurofibrillary tangles, which occur through intracellular deposit of aggregates of phosphorylated tau protein. ${ }^{[1]}$ The $A \beta$ protein originates through the cleavage of a transmembrane protein called the amyloid precursor protein (APP), and this precursor has an $A \beta$ domain inserted in the membrane that is cleaved by two types of protease enzymes called secretases. ${ }^{[2]}$ When the cleavage is performed by the $a$-secretase enzyme, a non-amyloid soluble fragment (p3) is formed. If the protein is cleaved by the $\beta$-secretase enzyme, the $A \beta$ amyloid fragment is formed, which is insoluble and rich in crossed $\beta$ sheets, and deposit in brain tissue is followed by aggregation and polymerization in the form of senile plaques. ${ }^{[1,3,4]} \mathrm{A}$ common hypothesis was that amyloid plaque formation was the main cause of dementia; however, this hypothesis has lost strength due to new studies that observed loss of synapses in regions of the brain where these plaques do not exist. ${ }^{[5]}$

The TAU protein is an important component of the neuronal cytoskeleton, mainly in the axons, and is responsible for the stabilization of microtubules. Aggregates of this proteinin thehyperphosphorylated state result in the formation of highly insoluble intracellular tangles with disruption of the cell cytoskeleton and consequent neuronal death. ${ }^{[4,5]}$ These, together with senile plaques, represent the pathological findings characteristic of Alzheimer's disease. When combined, these two events decrease the number of neuronal cells and consequently result in functional deficit of synapses and atrophy

Cite this article: Silva BYK, Lopes ASN, Maia PJS, Mar JM, Silva LS, Sanches EA, Corrêa GM, Bezerra JA, Carmo DFM. Chemical and Biological Evaluation of the Aqueous Extract of Peumus boldus Molina (Monimiaceae) Leaves. Extract on Pre-diabetic Subjects. Pharmacog Res. 2022;14(1):45-52. 
of the cerebral parenchyma, causing dementia. ${ }^{[6]}$ Many studies associate the accumulation of $A \beta$ protein as the activator in the hyperphosphorylation of the tau protein, but the factors that lead to these events are still unclear. ${ }^{[5]}$

Studies reveal that the accumulation of amyloid plaques can stimulate the production of reactive oxygen and nitrogen species (ROS and RNS), ${ }^{[5,6]}$ justifying the search for antioxidant compounds that can protect neurons from the oxidative processes generated by the accumulation of the amyloid plaques. Oxidative stress is characterized as an imbalance between the production of free radicals and the ability of the cell to defend against them. ${ }^{[6-10]}$ High oxygen consumption and relatively low levels of antioxidants result in the susceptibility of brain tissue to oxidative damage. Numerous oxidative stress biomarkers have been found in patients with Alzheimer's, including excessive lipid peroxidation, neuronal degeneration, protein oxidation, and DNA and RNA glycoxidation and oxidation. ${ }^{[6]}$

Studies also found that oxidative stress can increase the production and accumulation of the $\beta$-amyloid peptide and facilitate the phosphorylation and polymerization of the Tau protein, forming a vicious cycle that promotes initiation and progression of $\mathrm{AD} \cdot{ }^{[5]}$ Clinical studies in humans have not yet obtained effective results, ${ }^{[6]}$ for the treatment of $\mathrm{AD}$; therefore, interest in finding an effective therapy for $\mathrm{AD}$ remains high. One of the promising avenues for achieving this goal is to inhibit enzymes capable of degrading neurotransmitters that transmit the nerve impulse to the postsynaptic neuron through nicotinic and muscarinic receptors. One approach to treating $\mathrm{AD}$ to inhibit the $\mathrm{AChE}$ enzyme, in which main objective is to minimize the deficit in neurotransmitter molecules and enable an increase in signal transmission in patients affected by AD. ${ }^{[11,12]}$ Some chemically synthesized compounds display an affinity with the enzyme, the most relevant being donepezil, rivastigmine, tacrine, and recently galantamine. However, these compounds have low antioxidant potential and adverse side effects such as nausea, vomiting, dizziness, anorexia, abdominal pain, and headaches. These conditions encourage the scientific community to continue research to discover new molecules with inhibitory capacity against the AChE enzyme.

One of the active sites of AChE is called the "aromatic throat", site presents itself as a deep and narrow channel about $20 \AA$ deep. Its composition contains more than 50\% amino acids with conserved aromatic residues (Phe120, Phe288, Phe290, Phe330, Phe331, Trp84,Trp233, Trp279, Trp432, Tyr70, Tyr121, Try130, Try334, and Tyr442). ${ }^{[13]}$ Other active sites consist of the catalytic triad (Ser200, Glu327, and His440), anionic catalytic site (Trp84, Glu199, and Phe330), oxyanion cavity (Gly118, Gly119, and Ala201), and acyl group cavity (Phe288 and Phe290). ${ }^{[14]}$

Galantamine, recently discovered as an important enzyme inhibitor is an alkaloid found in species of the family Amaryllidaceae. Similar to this compound, other alkaloids also have important anticholinesterase activity, ${ }^{[15-19]}$ and are capable of reestablishing the neurotransmission system. Therefore, studies have explored these groups as promising natural inhibitors of acetylcholinesterase.

Every medicinal plant causes a therapeutic resource that is used to alleviate symptoms or cure diseases. One plant widely used for medicinal purposes is boldo, due to its extensive capacity to treat problems related to the stomach and liver, especially by people who commonly drink alcoholic beverages. One of the mechanisms of action of the ACh neurotransmitter is to increase intestinal motility; therefore, the chemical constituents present in boldo leaves could have the capacity to inhibit the catalytic action of AChE in the hydrolysis of ACh.

Boldo (Peumus boldus) is a plant native to the central and southern regions of Chile and belongs to the family Monimiaceae. ${ }^{[18]}$ This herb is widely consumed in Brazil and other countries around the world due to its wide spectrum of pharmacological effects. It is mainly indicated for the treatment of various infections in the digestive and hepatobiliary system. In addition to its role as a liver protector and digestive stimulant, $P$. boldus is traditionally used as an anti-inflammatory, antispasmodic, and nervous sedative agent. ${ }^{[18,20]}$ The aforementioned pharmacological properties are obviously associated with the chemical composition of the boldo leaves.

The most important active principles contained in the boldo leaves are alkaloids and flavonoids. Among alkaloid compounds, boldine is the most important active principle of $P$. boldus, and some works indicate that the anti-inflammatory activity and antioxidant properties of the species are related to this substance. . $7,18,20,21]^{2}$

Boldo leaves also have tannins, essential oil, flavonoids, and glycolipids. ${ }^{[18]}$ Its leaves are reported to contain sparteine; therefore, its use is not recommended during pregnancy, as this alkaloid can accelerate delivery (oxytocic activity). ${ }^{[22]}$

Considering the presence of alkaloids is major constituents of the species, this group of compounds might be healthy alternatives to synthetic inhibitors.

In this context, this work aimed to discover potential AChE inhibitors in the aqueous extract of leaves from a commercial sample of $P$. boldus and to evaluate the antioxidant activity of these samples using the free radical DPPH and ABTS methods, auto-oxidation of the $\beta$-system carotene/linoleic acid, and iron reduction (FRAP), as well as quantifying the content of total phenolic compounds.

\section{MATERIALS AND METHODS}

\section{Collection and identification of plant material}

Boldo leaves were obtained from a store in the city of Itacoatiara, AM, Brazil, in October 2018.

Botanical identification was carried out based on the analysis of diagnostic characteristics such as shape, phyllotaxis, and leaf indumentum. To confirm authenticity, the samples were compared to reference collections in virtual herbaria.

\section{Tea Preparation}

The plant material was subjected to the infusion process for $10 \mathrm{~min}$, according to the popular preparation method. The leaves of the boldo species were standardized at a concentration of $12 \mathrm{mg} \mathrm{ml}^{-1}$, then the solutions were stored in vials, frozen, and lyophilized. The obtained extract was abbreviated AEBL - Aqueous Extract Boldo Leaves.

\section{Mass Spectrometry Analysis}

The stock solution was prepared by weighing $5 \mathrm{mg}$ of the aqueous extract in a calibrated 5-ml volumetric flask using a calibrated analytical balance $( \pm 0.1 \mathrm{mg}$ ) and $\mathrm{MeOH}$ as solvent, to obtain a final concentration of $1 \mathrm{mg} \mathrm{ml}^{-1}$.

Then an intermediate solution was prepared to obtain the final solution with a concentration of $5 \mu \mathrm{g} \mathrm{ml}^{-1}$. These samples were analyzed by direct infusion in a mass spectrometer.

All mass spectra were acquired in monitoring mode (application Thermo LCQ Fleet Tune) using an LCQ Fleet ion-trap mass spectrometer (Thermo Frota LCQ, San Jose, CA, USA) with an electrospray ionization (ESI) interface and running in positive ion mode to perform ESI-MS and ESI-MSn analysis. Spectra were obtained from an average of at least 10 exams per spectrum. The samples were directly infused into the ion source through the syringe pump on the instrument $\left(10 \mathrm{ml} \mathrm{min}^{-1}\right)$. The analytical conditions of MS were spray voltage, $5 \mathrm{kV}$; gas sheath, 10 arb; auxiliary gas, 5 arb; sweep gas, 0 arb; capillary temperature, 200; capillary 
voltage, $40 \mathrm{~V}$; tube lens, $115 \mathrm{~V}$; mass range, $\mathrm{m} / z 200$ to 400 . Helium was used as a gas collision, and ESI-MSn spectra were obtained using collision energies ranging from 20 to $30 \%$.

\section{Antioxidant Activity}

Antioxidant capacity analyzed by DPPH, ABTS, FRAP, and b-carotene/linoleic acid cooxidation methods

The tests were carried out at the Laboratory of Nanostructured Polymers (NANOPOL) at the UFAM. The samples were solubilized in $\mathrm{MeOH}$ P.A. at $1.0 \mathrm{mg} \mathrm{ml}^{-1}$ and subjected to the following analyzes.

\section{DPPH Assay}

For this assay, $10 \mu \mathrm{L}$ of the sample was added to $190 \mu \mathrm{L}$ of the DPPH solution $(100 \mu \mathrm{M})$ and incubated in a dark environment for $30 \mathrm{~min}$. Afterwards, absorbance readings were performed in a Microplate Reader at $515 \mathrm{~nm}$ (Epoch 2, Biotek). A Trolox standard curve from 100 to $1500 \mu \mathrm{M}(\mathrm{y}=-0.0004 \mathrm{x}+0.7071, R 2=0.9931)$ was built and the results were expressed in $\mu \mathrm{M}$ of Trolox Equivalents. ${ }^{[1,23]}$

\section{ABTS Assay}

For the ABTS assay, $2 \mu \mathrm{L}$ of the sample was added to $200 \mu \mathrm{L}$ of the ABTS. ${ }^{+}$solution (0.70 ABS) and incubated in a dark environment for $6 \mathrm{~min}$. Then the absorbance reading was carried out in a Microplate Reader at $750 \mathrm{~nm}$ (Epoch 2, Biotek). A standard Trolox curve was made from 125 to $2000 \mu \mathrm{M}(\mathrm{y}=-0.0003 \mathrm{x}+0.7351, R 2=0.9995)$ and the results were expressed in $\mu \mathrm{M}$ of Trolox Equivalents. ${ }^{[23]}$

\section{Iron reduction (FRAP)}

The FRAP reagent was prepared beforehand by adding acetate buffer $\left(0.3 \mathrm{~mol} \mathrm{~L}^{-1}, \mathrm{pH}=3.6\right)$, TPTZ solution $(10 \mathrm{mM})$ and $\mathrm{FeCl}_{3} \cdot 6 \mathrm{H}_{2} \mathrm{O}$ $(20 \mathrm{mM})$, in the ratio $10: 1: 1$. On a microplate, an aliquot of $9 \mu \mathrm{L}$ of the sample $\left(500 \mu \mathrm{g} \mathrm{ml}^{-1}\right)$ was mixed with $27 \mu \mathrm{L}$ of ultrapure water and added to $270 \mu \mathrm{L}$ of the FRAP reagent. The microplate was incubated for $30 \mathrm{~min}$ at $37^{\circ} \mathrm{C}$ and the absorbance measured at $595 \mathrm{~nm}$ using a microplate reader (Epoch 2, Biotek). The results were obtained by the regression equation of the curve obtained from the standard solution of ferrous sulfate ( 250 to $2000 \mu \mathrm{M}$ ) and expressed in the Fe (II) [ $\mu \mathrm{M} \mathrm{Fe}(\mathrm{II}) \mathrm{g}^{-1}$ ] extract. The assay was performed in triplicate. ${ }^{[23]}$

\section{$\beta$-carotene/linoleic acid cooxidation}

The Oxidation Inhibition assay of the $\beta$-carotene/linoleic acid system consists of the reaction mixture of linoleic acid, Tween $40, \beta$-carotene, and water saturated with oxygen, with absorbance between 0.6 and 0.7 at $470 \mathrm{~nm}$. First, $250 \mu \mathrm{L}$ of this reactive mixture and $10 \mu \mathrm{L}$ of samples $\left(500 \mu \mathrm{g} \mathrm{ml}^{-1}\right)$ were added to a microplate and incubated at $37^{\circ} \mathrm{C}$, and then absorbance readings were performed in a Microplate Reader (Epoch 2, Biotek). Results were expressed as percentage of oxidation inhibition. ${ }^{[24]}$

\section{Determination of total phenols}

For the assay of total phenols, the sample was added to a reaction mixture (1:1) of Folin Cicoalteu reagent and sodium bicarbonate (6\%), maintained in the dark for $90 \mathrm{~min}$ for further analysis in a Microplate Reader at $725 \mathrm{~nm}$ (Epoch 2, Biotek). The standard curve for gallic acid was made from 7.8 to $1000 \mu \mathrm{g} \mathrm{ml}^{-1}(\mathrm{y}=0.0028 \mathrm{x}+0.2847, R 2=0.9931)$, and the results are expressed as milliequivalents of gallic acid per gram of sample.

\section{Assessment of acetylcholinesterase inhibition in vitro}

The enzymatic activity of acetylcholinesterase was determined on microplates using the Ellman spectrophotometric method. ${ }^{[11]}$ The enzyme used was acetylcholinesterase (AChE) from Electrophorus electricus type VI (Sigma ${ }^{\oplus}$ ), 5,5'-dithiobis (2-nitrobenzoic acid) (DTNB), iodinated acetylcholine substrate and eserine, Sigma standard. In each well of the microplates, $25 \mu \mathrm{L}$ of $15 \mathrm{mM}$ iodinated acetylcholine, $125 \mu \mathrm{L}$ of DTNB, $50 \mu \mathrm{L}$ of $50 \mathrm{mM}$ Tris- $\mathrm{HCl}$ buffer $\mathrm{pH} 8.0$, and $25 \mu \mathrm{L}$ of the plant extracts at a concentration of $1 \mathrm{mg} / \mathrm{ml}$ were added. $\mathrm{MeOH}$ and tris- $\mathrm{HCl}$ were used as controls and eserine $(10 \mu \mathrm{M})$ as standard inhibitor. Absorbance was measured at $405 \mathrm{~nm}$ using a Thermoplate ${ }^{\circledast}$ microplate reader, model TP-reader, with 15-sec intervals. After these readings, $25 \mu \mathrm{L}$ of $0.22 \mathrm{U} \mathrm{ml}^{-1}$ acetylcholinesterase were added to the wells. Absorbances were measured again at $405 \mathrm{~nm}$, with 15 -sec intervals. Increases in absorbance due to spontaneous substrate hydrolysis were corrected by subtracting the reaction rate before addition of the enzyme. Percentage of inhibition was calculated by comparing sample rates to controls. All assays were performed in triplicate. Enzymatic activity and percentage of AChE inhibition were calculated using the Microsoft $^{\oplus}$ Excel program.

\section{In silico evaluation against AChE enzyme by molecular docking}

All structures of the major compounds identified in the samples were designed in ACD/Chemsketch and saved in sdf format. Furthermore, binder structures were previously verified by Marvin Srtch 15.4.207 for anchorage studies. Before the docking calculations, Autodock Tools 1.5.6 was used to prepare the protein and ligand structures according to the following steps: (1) definition of the grid for each target protein, considering each active site previously described by crystallographic studies; (2) verification for each torsional ligand structure and addition of polar hydrogens, Gaigster, and Kollman charges; and (3) saving all molecules pdbqt format.

Autodock Vina was used to calculate the affinity energies for each complex. After the structures were selected, to observe the results in silico by molecular docking, the Discovery Studio Visualizer program was used.

\section{RESULTS AND DISCUSSION}

\section{Constituents identified in commercial $P$. boldus samples}

The AEBL was analyzed in a direct infusion mass spectrometer in positive mode. The obtained spectra presented several similar peaks with $[\mathrm{M}+\mathrm{H}]^{+}$pair, but with different intensities. Peaks indicate masses that are compatible with alkaloids already reported for P. boldus as well as some alkaloids observed in studies about other species in the same family. The peaks at $m / z 286,300,328,330,342$, and $355\left([\mathrm{M}+\mathrm{H}]^{+}\right)$ were detected in greater relative abundance (Figure S1 - Supporting information), the others were observed with low intensity.

Some of these peaks can be identified, such as the ion at $m / z 286$ $([\mathrm{M}+\mathrm{H}]+)$, which is compatible with the quasi-molecular ion $\left([\mathrm{M}+\mathrm{H}]^{+}\right)$ of Coclaurine, an alkaloid already reported for this species. ${ }^{[16,19]}$ Its fragmentation allows detection of the daughter ion at $\mathrm{m} / \mathrm{z} 269$ with greater intensity, in addition to the ions at $m / z 237,178,175,145,143$, 137 , and 107 , which are compatible with fragmentation data for this substance.

The ion observed at $m / z 300\left([\mathrm{M}+\mathrm{H}]^{+}\right)$is compatible with the quasimolecular ion $\left([\mathrm{M}+\mathrm{H}]^{+}\right)$of $N$-methylcoclaurine, an alkaloid already reported in $P$. boldus, ${ }^{[25]}$ fragmentation revealed daughter ions at $\mathrm{m} / \mathrm{z}$ $269,237,192,175,145,143,137$, and 107 , which were compatible with the fragmentation data of $\mathrm{N}$-methylcoclaurine.

Another ion observed was $m / z 328\left([\mathrm{M}+\mathrm{H}]^{+}\right)$, compatible with the quasi molecular ion $\left([\mathrm{M}+\mathrm{H}]^{+}\right)$of boldine, an aporphinic alkaloid reported in the species. ${ }^{[26]}$ When fragmented, daughter ions were detected at $m / z 297$ 


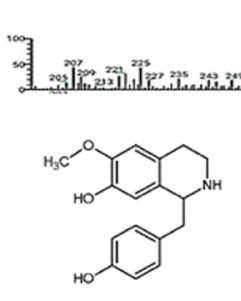

(1)

\section{(4)}
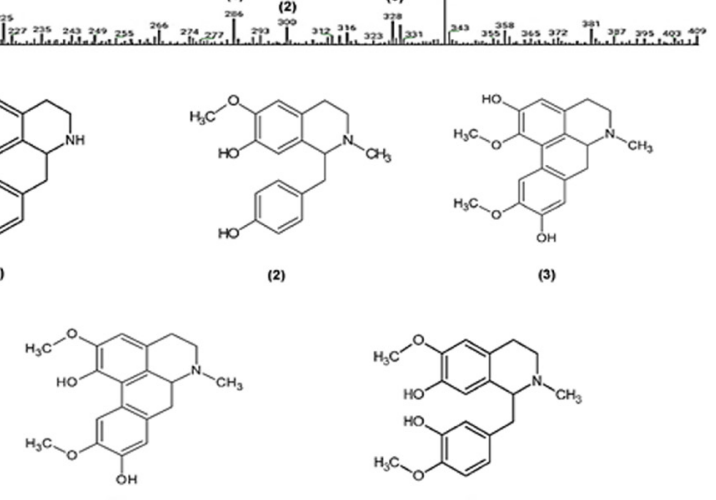

(3)

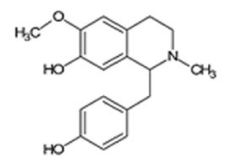

(2)

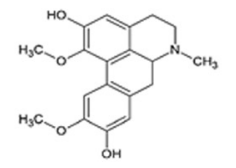

(3)
Figure S1: Total ion chromatogram of the AEBL sample and the main identified constituents: 1 - Coclaurine; 2 - N-methylcoclaurine; 3 - Boldine and Isoboldine; 4 - N-methyllaurotetanine.

and 268, in agreement with the literature data on the fragmentation of this alkaloid.

The mass analysis of the $m / z 328$ ion, when subjected to fragmentation into $\mathrm{MS}^{\mathrm{n}}$, exhibited an initial loss of $31 \mathrm{Da}$, and sequential losses of 32 $\mathrm{Da}$ and $28 \mathrm{Da}$, suggesting that it is an aporphine alkaloid containing an $\mathrm{N}$-methyl and a methoxyl adjacent to a hydroxyl in the A ring. The alkaloids suggested for this spectrum are boldine and isoboldine, as they have the same ion mass of $m / z 328 .^{[16,17,19,27]}$

The aporphine alkaloid laurotetanine was identified by fragmentation of the ion $\mathrm{m} / z 328$ and through the formation of ions at $\mathrm{m} / z 311,279,264$, and 236. The initial loss of $17 \mathrm{Da}$ was attributed to the $\mathrm{NH} 3$ group, which indicates that nitrogen present in the molecule is linked to a hydrogen and not to the methyl group. ${ }^{[17,28]}$

The $m / z 330\left([\mathrm{M}+\mathrm{H}]^{+}\right)$ion is compatible with the reticuline alkaloid. When fragmented, the daughter ions were generated at $m / z 299,267$, 192,175 , and 137, which are values noted in the literature. ${ }^{[25]}$

The structure of the $\mathrm{m} / \mathrm{z} 342$ alkaloid was confirmed by comparing existing data in the literature. ${ }^{[17,28]}$ The $m / z 342$ ion, when submitted to fragmentation analysis, evidenced sequential losses of 31,15 , and $31 \mathrm{Da}$, suggesting an aporphinic structure containing an adjacent $N$-methyl and methoxyl in the A ring; such fragments are compatible with the $\mathrm{N}$-methyllaurotetanine alkaloid.

The $m / z 356$ ion $\left([\mathrm{M}+\mathrm{H}]^{+}\right)$, which is compatible with the quasi-molecular ion $\left([\mathrm{M}+\mathrm{H}]^{+}\right)$of glaucine, in its fragmentation, could detect the daughter ions of $\mathrm{m} / \mathrm{z} 325,294,279,251$, and 236 (Table 1 ).

Evaluation of the mass spectra identified the presence of three phenolic compounds in the sample, Figure 1 . The ion at $m / z 727$, when subjected to fragmentation into $\mathrm{MS}^{\mathrm{n}}$, showed an initial loss of $132 \mathrm{Da}$, corresponding to dehydrated pentose, and sequential losses of $162 \mathrm{Da}$ and $146 \mathrm{Da}$, suggesting the presence of hexose and rhamnose, respectively. Such fragments, in comparison with literature data, are compatible with the flavonoid Luteolin-pentosyl-glucosylrhamnose. The ion at $m / z 741$ is compatible with the flavonoid kaempferol - 3-O-glycosyl-rhamnosylrhamnose, when sequential losses of $132 \mathrm{Da}$ are observed, referring to one dehydrated pentose unit and two $146 \mathrm{Da}$, pertaining to losses of two rhamnose units. ${ }^{[17]}$

The compound identified by the ion at $\mathrm{m} / z 633$ showed a typical fragmentation pattern of chlorogenic acids. Through the loss of $341 \mathrm{Da}$,
Table 1: Alkaloids identified in the AEBL extract.

\begin{tabular}{|c|c|c|c|c|}
\hline $\begin{array}{l}\text { Precursor } \\
\text { ion } \mathrm{m} / \mathrm{z}\end{array}$ & $\begin{array}{l}\text { Fragmented } \\
\text { ions } \mathrm{m} / \mathrm{z}\end{array}$ & Identification & MF & Refs. \\
\hline 286 & $\begin{array}{c}269,237,178 \\
175,145,143 \\
137, \text { and } 107\end{array}$ & Coclaurine & $\mathrm{C}_{17} \mathrm{H}_{19} \mathrm{NO}_{3}$ & {$[16,19]$} \\
\hline 300 & $\begin{array}{c}269,237,192 \\
175,145,143 \\
137, \text { and } 107\end{array}$ & $N$-methylcoclaurine & $\mathrm{C}_{18} \mathrm{H}_{21} \mathrm{NO}_{3}$ & [25] \\
\hline 314 & 297,265 & Laurolitsine & $\mathrm{C}_{18} \mathrm{H}_{19} \mathrm{NO}_{4}$ & [17] \\
\hline 316 & 299,178 & Norreticuline & $\mathrm{C}_{18} \mathrm{H}_{21} \mathrm{O}_{4}$ & {$[17]$} \\
\hline 328 & $\begin{array}{l}297,265,237 \\
\quad \text { and } 205\end{array}$ & Boldine & $\mathrm{C}_{19} \mathrm{H}_{21} \mathrm{NO}_{4}$ & {$[25,26]$} \\
\hline 328 & $\begin{array}{c}297,265,237 \\
165\end{array}$ & Isoboldine & $\mathrm{C}_{19} \mathrm{H}_{21} \mathrm{NO}_{4}$ & {$[16,27]$} \\
\hline 328 & $\begin{array}{c}311,279,264 \\
236\end{array}$ & Laurotetanine & $\mathrm{C}_{19} \mathrm{H}_{21} \mathrm{NO}_{4}$ & {$[17,28]$} \\
\hline 330 & $\begin{array}{c}299,267,192 \\
175, \text { and } 137\end{array}$ & Reticuline & $\mathrm{C}_{20} \mathrm{H}_{23} \mathrm{NO}_{4}$ & {$[17,25]$} \\
\hline 342 & $\begin{array}{l}311,296,280 \\
265,253,237\end{array}$ & $N$-methyllaurotetanine & $\mathrm{C}_{20} \mathrm{H}_{23} \mathrm{NO}_{4}$ & {$[17,28]$} \\
\hline 342 & $\begin{array}{c}296,279,264 \\
248\end{array}$ & Isocoridine & $\mathrm{C}_{20} \mathrm{H}_{23} \mathrm{NO}_{4}$ & [17] \\
\hline 356 & $\begin{array}{c}325,294,279 \\
251, \text { and } 236\end{array}$ & Glaucine & $\mathrm{C}_{21} \mathrm{H}_{25} \mathrm{NO}_{4}$ & {$[25,28]$} \\
\hline
\end{tabular}

MF = Molecular Formula

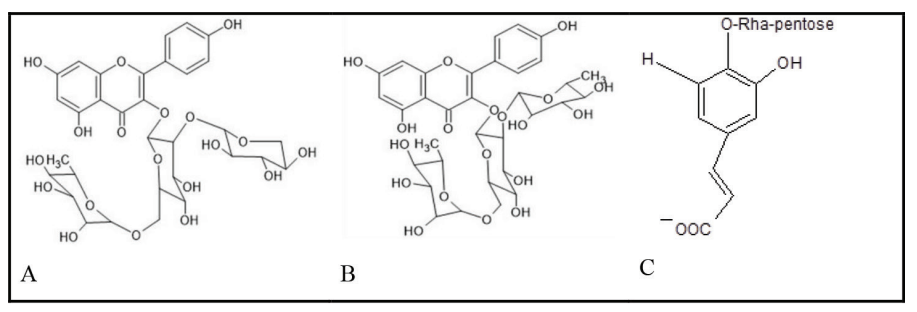

Figure 1: Phenolics identified in the AEBL extract: A- Luteolin-pentosylglycosyl-rhamnose; B - Caempferol-3-O-glycosyl-rhamnosyl-rhamnose; and C - Caffeoylquinic phenolic acid glycoside.

the cinnamoyl glycoside part was identified and, through the loss of 323 $\mathrm{Da}$, the caffeoyl glycoside unit was identified. These fragments suggest the glycoside caffeoylquinic phenolic acid. ${ }^{[29]}$

\section{Antioxidant activity and quantification of total phenolic compounds}

Table 2 presents the results of the antioxidant activity of the AEBL extract evaluated by the DPPH, ABTS, FRAP methods and by the beta-carotene/ linoleic acid system, in addition to the quantification results of the total phenolics.

$\mathrm{DPPH}$ is sequestered by phenolic compounds through two mechanisms: 1) possible donation of hydrogen to stabilize the radical compound; 2) donation of electrons from the phenoxide anion to DPPH. For these mechanisms, phenolics can participate together with flavonoids as an antioxidant by presenting free phenolic hydroxyl radicals and by the bioavailability of conjugation. ${ }^{[23,30]}$ However, this high free radical scavenging activity observed in the $P$. bordo extract is not just related 
Table 2: Results of the antioxidant activity of the aqueous extract of Peumus boldus.

\begin{tabular}{|c|c|c|c|c|c|}
\hline $\begin{array}{l}\frac{0}{0} \\
\frac{\varepsilon^{\circ}}{n ๊}\end{array}$ & $\begin{array}{l}\text { T } \\
\text { E } \\
\vdots \\
\vdots \\
\vdots\end{array}$ & 在 & 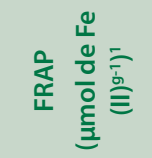 & 高 & 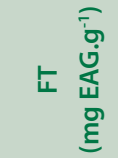 \\
\hline AEBL & $1513.6 \pm 1.2$ & $1928.1 \pm 5.7$ & $1512.7 \pm 4.2$ & $81.2 \pm 1.3$ & $82.4 \pm 0.9$ \\
\hline
\end{tabular}

${ }^{1} \mu \mathrm{mol}$ of Fe (II) $\mathrm{g}^{-1}$ : power of reduction in $\mu$ mol of Fe (II) per gram of sample; $2 \mathrm{mEAG} \mathrm{g}^{-1}$ : equivalent to gallic acid per gram of sample; ${ }^{3} \mu \mathrm{M} \mathrm{ET}$ : antioxidant capacity equivalent to trolox.

to the presence of phenolic compounds because the extract exhibited a low concentration of phenolics $\left(82.804 \pm 0.9 \mathrm{mg} \mathrm{EAG} \mathrm{g}^{-1}\right)$. These results indicate that the observed oxidizing activity may be related to the presence of alkaloids. Previous studies have evidenced the antioxidant potential of alkaloids. Giordani et al. ${ }^{[15]}$ proved by the DPPH method the antioxidant activity of the alkaloids lycorine and boldine with $\mathrm{IC}_{50}$ values of $0.326 \mathrm{mM}$ and $0.0552 \mathrm{mM}$, respectively. Other compounds, such as helindicine and lycopsamine, both alkaloids, containing a laconic ring in their structuret, ${ }^{[31]}$ erisodine, hydroxyerisodine, melosmine, and O-Methyl-moschatoline, with the presence of the oxaporphine nucleus, have an expressive capacity to capture the DPPH radical. ${ }^{[32]}$ Capturing the activity of reactive oxygen species (ROS) in alkaloid groups may be related to the exceptional redox property conferred to nitrogen, ${ }^{[16,17,20]}$ present in the structures of these secondary metabolites.

Treatment of $\mathrm{AD}$ through antioxidant therapies can prevent or at least attenuate organic deterioration due to excessive oxidative stress. Significant evidence indicates oxidative stress in the progression of $\mathrm{AD}$, leading to progressive and significant loss of specific neuronal cells, contributing to the pathogenesis of the disease. ${ }^{[4]}$ Thus, the discovery of constituents with antioxidant properties is very beneficial to delay the progression of the disease.

In the ABTS method, the extract also presented expressive antioxidant activity $(1928.1 \pm 5.7 \mu \mathrm{M} \mathrm{ET})$, which is related to the presence of alkaloids that act as good electron donors.

The methodology using $\beta$-carotene autooxidation measures the capacity of the extract to inhibit $\beta$-carotene oxidation against linoleic acid. The AEBL presented antioxidant activity with a percentage of $81.2 \pm 1.3 \%$. This activity is directly related to the total phenolic content in the extract. The extract managed to reduce a significant amount of $\mathrm{Fe}^{3+}$ in $\mathrm{Fe}^{2+}$ $\left(1512.7 \mu \mathrm{MFe}^{2+} \mathrm{mg}^{-1}\right)$. The antioxidant activity observed is due to the presence of phenolics and was complimented by the presence of alkaloid. These molecules can donate hydrogen radicals to pair with other available radicals, impeding oxidation and stabilizing the system. ${ }^{[33]}$

\section{Assessment of acetylcholinesterase inhibition in vitro}

The AEBL did not exhibit inhibitory activity to acetylcholinesterase at the evaluated concentration of $1 \mathrm{mg} / \mathrm{ml}$. For the AEBL, the literature reports a potent inhibitory action of aqueous extracts of $P$. boldus leaves at a concentration greater than $\left.1 \mathrm{mg} \mathrm{ml}^{-1}\right),{ }^{[18,20]}$ suggesting that the in vitro test for the AEBL should be repeated at a higher concentration.

\section{Molecular Docking}

The results for the dockings of isoboldine, boldine, coclaurine, leurotetanine, $N$-methyllaurotetanine, reticuline, and $N$-methylcoclaurine in AChE were practically located in the catalytic cavity (Trp84). The Trp84 residue is located next to the triad (Ser200 - His440 - Glu327) and is considered the main residue located at the end of the "aromatic throat". ${ }^{[13,14]}$ Trp84 has been used in many other molecular docking
Table 3: Energy results of the alkaloids identified in the aqueous extract of $P$. boldus leaves.

\begin{tabular}{cc}
\hline Compounds & Binding energy $(\mathrm{kcal} / \mathrm{mol})$ \\
\hline$N$-methyllaurotetanine & -10.1 \\
Isoboldine & -10.0 \\
Boldine & -9.9 \\
Laurolitsine & -9.7 \\
$N$-methylcoclaurine & -9.6 \\
Coclaurine & -9.4 \\
Reticuline & -9.1 \\
\hline
\end{tabular}

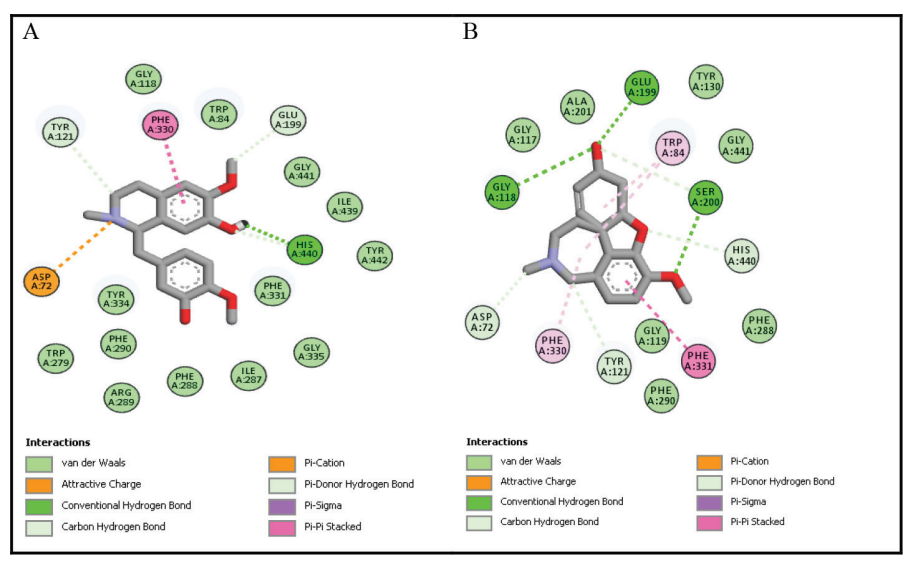

Figure S2: Result of molecular docking using the Autodock program for a) reticuline; b) galantamine.

studies as an important marker of successful enzyme inhibition. The isoquinoline alkaloid reticuline was the only compound that showed weaker interaction with the Trp84 residue, as this type of ligand recognition may justify a higher value of free binding energy in the enzyme. The higher the energy value, the lower the binding affinity and the higher the drug concentration required to inhibit enzyme activity ${ }^{[11,34]}$ Although reticuline does not present a docking energy value as satisfactory as the other alkaloids identified in the $P$. boldus sample (Table 3), it exhibits an inhibitory capacity due to the other electrostatic interactions observed with the amino acids of the enzyme.

The inhibitory capacity of reticuline is justified by Van der Waals interactions with Gly 118, Trp84, Try 334, Phe 290, and Phe 288 residues that belong to the catalytic triad, oxyanion cavity, peripheral anionic site, and acyl binding site as well as electrostatic interactions, for example the $\pi$-cation-type interaction with the Asp 72 residue pertaining to the peripheral anionic site (PAS), hydrogen bonding with the His 440 residue of the catalytic site and the hydroxyl group of the molecule, and the $\pi-\pi$ type-stacking interaction with Phe 330 from the catalytic triad (Figure 2 and S2a).

The analysis of the AChE complex with galantamine, the reference molecule in this study, found several interactions in the active site of the enzyme, justifying its ability to stabilize the free energy of the drugreceptor complex $\left(-9.6 \mathrm{kcal} \mathrm{mol}^{-1}\right)$ and the inhibitory potential of this substance. The interactions found include $\pi-\pi$ stacking-type interaction with Trp 84 and Phe 330 residues of the catalytic triad, hydrogen bonding with residues Gly 118, Glu 199, and Ser 200 from the catalytic site, and the oxyanion cavity of the enzyme with the hydroxyl and methoxyl groups of galanthamine, $\pi$-sigma-type interaction with the Phe 331 residue with the aromatic ring of the molecule, Van der Waals interaction 


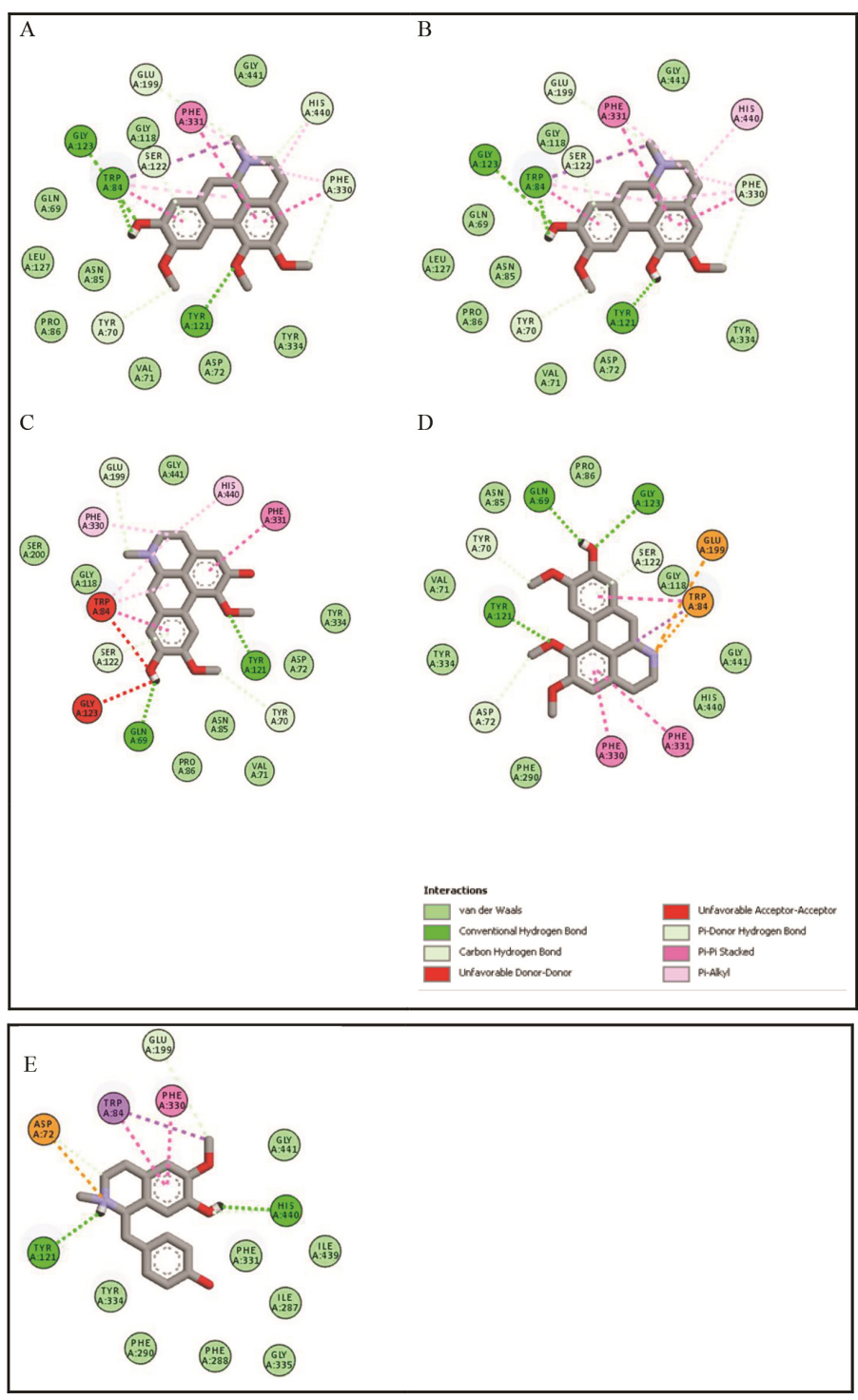

Figure S3: Molecular docking result for: $\mathrm{A}-\mathrm{N}$ - methyllaurotetanine; $\mathrm{B}$ - isoboldine; C-boldine, D - laurotetanine, and E - N-methylcoclaurine, using the Autodock program.

with the anionic subsite (oxygen channel) with the Ala 201 residue, and with the catalytic acylation site (CAS) formed by Phe 290 and Phe 288 (Figure S2b).

As mentioned above, the lower the molecular docking energy, the stronger the enzyme inhibition process for the evaluated substance. $\mathrm{N}$-methyllaurotetanine exhibited the best value, followed by isoboldine, boldine, laurotetanine, and $N$-methylcoclaurine, the latter displaying the same value as galantamine (an important enzyme inhibitor).

$\mathrm{N}$-methyllaurotetanine and isoboldine have a hydrogen bond interaction (stronger interaction) of the Trp 84 residue, which belongs to the catalytic triad, with the hydroxyl group of these alkaloids. This type of interaction is not observed in the other substances, justifying its higher energy values (Figures 3 and S3a-e). Hydrogen bonding was also observed at the Try 121 residue of the peripheral anionic site.

Boldine did not have any favorable interaction for the formation of the hydrogen bond of the hydroxyl group with the Trp 84 and Gly 123 residues; however, this type of bond was observed with the Try 121 residue and the methoxyl group. We verified $\pi$-alkyl-type interactions, with the residue His 440 of the catalytic site and with the residue Phe 330 of the catalytic triad, and $\pi-\pi$ stacking of the residue Phe 331 , belonging to the oxyanion cavity, with the aromatic ring of the molecule.

Laurotetanine and $\mathrm{N}$-methylcoclaurine exhibited similar interactions. The main differences observed include the presence of electrostatic interaction of the $\pi$-cation type between the residues Glu 199 and Trp 84 with the nitrogen of the aporphine alkaloid leurotetanine, and the presence of hydrogen bonding between the residue His 440 and the hydroxyl group of the alkaloid $N$-methylcoclaurine, as well as between the Try 121 residue and the proton.

\section{CONCLUSION}

The aqueous extract of Peumus boldus leaves exhibited important secondary metabolites, such as flavonoids, phenolic compounds, and alkaloids. These constituents were responsible for the antioxidant activity observed in the DPPH, ABTS, and FRAP methods and beta-carotene/ linoleic acid system. Such results suggest that the studied sample can protect the neurons from the oxidative processes generated by the pathological processes of Alzheimer's disease. These activities correlate the promising results of the AChE enzyme inhibition. Despite the negative result of the extract for its in vitro inhibitory potential of the enzyme, the alkaloids identified in the sample were considered active for in silico anticholinesterase activity. The substances isoboldine, boldine, coclaurine, leurotetanine, N-methyllaurotetanine, reticuline, and $\mathrm{N}$-methylcoclaurine were able to inhibit the enzyme, with the alkaloid $\mathrm{N}$-methyllaurotetanine achieving the best inhibition. These data allow us to conclude that the aqueous extract of boldo leaves could be active at a concentration higher than $1 \mathrm{mg} \mathrm{ml}^{-1}$ and future studies are needed to fractionate and purify the fractions to isolate the molecules responsible for the observed inhibition.

\section{ACKNOWLEDGEMENT}

The authors would like to acknowledge Programa de Pós-Graduação em Ciência e Tecnologia para Recursos Amazônicos (PPGCTRA - UFAM), Fundação de Amparo à Pesquisa do Estado do Amazonas - FAPEAM (process $n^{\circ}$. 001/2021 - Mulheres na Ciência; process $n^{\circ}$. 005/2019), PROPESP/UFAM-CNPq (process $n^{\circ}$. 041/2016 and 008/2018), We are also grateful to the Herbarium from INPA and CESIT for the kindly support, Coordenação de Aperfeiçoamento de Pessoal de Nível Superior - Brasil (CAPES), Conselho Nacional de Desenvolvimento Científico - CNPq and Universal amazonas, n. 062. 0101076/2018.

\section{CONFLICT OF INTEREST}

The authors declare that there is no conflict of interest.

\section{ABBREVIATIONS}

AD: Alzheimer's disease; DPPH: (2,2-diphenyl-1-picrylhydrazyl); ABTS: [2,2'-azino-bis(3-ethylbenzothiazoline)-6-sulfonic acid]; FRAP: Ferric Reducing Antioxidant Power; ESI: Electrospray Ionization; AChE: Acetylcholinesterase; Ach: Acetylcholine; AEBL: Aqueous Extract Boldo Leaves; ROS: Reactive Oxygen Species.

\section{REFERENCES}

1. Nie $Q$, Du XG, Geng MY. Small molecule inhibitors of amyloid $\beta$ peptide aggregation as a potential therapeutic strategy for Alzheimer's disease. Acta Pharmacol Sin. 2011;32(5):545-51. doi: 10.1038/aps.2011.14, PMID 21499284.

2. Krasnovskaya O, Naumov A, Guk D, Gorelkin P, Erofeev A, Beloglazkina E, et al. Copper coordination compounds as biologically active agents. Int J Mol Sci. 2020;21(11):1-38. doi: 10.3390/ijms21113965, PMID 32486510.

3. Soreghan B, Kosmoski J, Glabe C. Surfactant properties of Alzheimer's $A \beta$ peptides and the mechanism of amyloid aggregation. J Biol Chem. 1994;269(46):28551-4. doi: 10.1016/S0021-9258(19)61939-3, PMID 7961799. 
4. Cook NP, Torres $V$, Jain D, Martí AA. Sensing amyloid- $\beta$ aggregation using luminescent dipyridophenazine ruthenium (II) complexes. J Am Chem Soc. 2011;133(29):11121-3. doi: 10.1021/ja204656r, PMID 21714574.

5. Näslund J, Haroutunian V, Mohs R, Davis KL, Davies $P$, Greengard $P$, et al. Correlation between elevated levels of amyloid $\beta$-peptide in the brain and cognitive decline. JAMA. 2000;283(12):1571-7. doi: 10.1001/jama.283.12.1571 PMID 10735393.

6. Wang $Y$, Yan $T$, Lu H, Yin $W$, Lin B, Fan $W$, et al. Lessons from anti-amyloid- $\beta$ immunotherapies in Alzheimer disease: aiming at a moving target. Neurodegener Dis. 2017;17(6):242-50. doi: 10.1159/000478741, PMID 28787714.

7. Barbosa AT, Da Silva VHN, Silva BYK da, Lopes A da SN, Guesdon IR, Maia PJS, et al. Chemical Composition and Biological Activities of Essential Oils from Fresh Vismia guianensis (Aubl.) Choisy and Vismia cayennensis (Jacq.) Pers. Leaves. Res Soc Dev. 2021;10(8):e37410817440.

8. Maia PJS, De Aguiar I, Dos Santos Velloso M, Zhang D, Dos Santos ER, De Oliveira JR, et al. Singlet oxygen production by a polypyridine ruthenium (II) complex with a perylene monoimide derivative: A strategy for photodynamic inactivation of Candida albicans. J Photochem Photobiol A. 2018;353:536-45. doi: 10.1016/j.jphotochem.2017.12.020.

9. Dos Santos RD, De Fatima Freire dos Santos S, Da Silva Moura F, Maia PJS, Da Fonseca BT, De Almeida Santos RH, et al. A nickel (II) coordination polymer derived from a tridentate Schiff base ligand with N,O-donor groups: synthesis, crystal structure, spectroscopy, electrochemical behavior and electrocatalytic activity for $\mathrm{H} 2 \mathrm{O} 2$ electroreduction in alkaline medium. Transit Met Chem. 2017;42(4):301-10. doi: 10.1007/s11243-017-0133-0.

10. Maia PJS, Cruz JF, De Freitas FA, De Fátima Freire dos Santos S, De Souza EA. Photophysical properties of a perylene derivative for use as catalyst in ethanol eletrooxidation. Res Chem Intermed. 2019;45(11):5451-72. doi: 10.1007/s11164019-03911-3.

11. Santos DC, Henriques RR, De Junior MAdAL, Farias $A B$, Nogueira $T L d C$, Quimas JVF, et al. Acylhydrazones as isoniazid derivatives with multi-target profiles for the treatment of Alzheimer's disease: radical scavenging, myeloperoxidase/acetylcholinesterase inhibition and biometal chelation. Bioorg Med Chem. 2020;28(10). doi: 10.1016/j.bmc.2020.115470.

12. Jung M, Park M. Acetylcholinesterase inhibition by flavonoids from Agrimonia pilosa. Molecules. 2007;12(9):2130-9. doi: 10.3390/12092130, PMID 17962731.

13. XuY, Colletier JP, Weik M, Jiang H, Moult J, Silman I, et al. Flexibility of aromatic residues in the active-site gorge of acetylcholinesterase: $X$-ray versus molecular dynamics. Biophys J. 2008;95(5):2500-11. doi: 10.1529/biophysj.108.129601, PMID 18502801

14. Kryger G, Silman I, Sussman JL. Three-dimensional structure of a complex of E2020 with acetylcholinesterase from Torpedo californica. J Physiol Paris. 1998;92(3-4):191-4. doi: 10.1016/s0928-4257(98)80008-9, PMID 9789806.

15. Giordani RB, Pagliosa LB, Henriques AT, Zuanazzi JAS, Dutilh JHA. Investigação do potencial antioxidante e anticolinesterásico de Hippeastrum (Amaryllidaceae). Quim Nova. 2008;31(8):2042-6. doi: 10.1590/S0100-40422008000800024.

16. Fofana S, Ziyaev R, Diallo SK, Camara M, Aripova SF. Alkaloids of Annona senegalensis. Chem Nat Compd. 2013;49(3):587-8. doi: 10.1007/s10600-0130683-0.

17. Torres-Vega J, Gomez-Alonso S, Perez-Navarro J, Pastene-navarrete E. Green extraction of alkaloids and polyphenols from Peumus boldus Leaves with natural deep eutectic. Plants. 2020;9(242):2-17.

18. Da S. N. Lopes A, R. Guesdon I, M. Corrêa G, S. Silva L, M. Mar J, A. Sanches E, et al. Chemical composition and biological activities of the essential oil of Peumus boldus molina (Monimiaceae). Rev Virtual Quim. 2020;12(2):433-46 doi: 10.21577/1984-6835.20200035

19. Fofana S, Keita A, Balde S, Ziyaev R, Aripova SF. Alkaloids from leaves of Annona muricata. Chem Nat Compd. 2012;48(4):714. doi: 10.1007/s10600-012-0363-5.

20. Del Valle JM, Rogalinski T, Zetzl C, Brunner G. Extraction of boldo (Peumus boldus M.) leaves with supercritical CO 2 and hot pressurized water. Food Res Int. 2005;38(2):203-13. doi: 10.1016/j.foodres.2004.09.010.

21. Barbosa-Filho JM, Piuvezam MR, Moura MD Silva MS, Lima KVB, Da-Cunha $E V L$, et al. Anti-infl ammatory activity of alkaloids: A twenty-century review. Rev bras farmacogn. 2006;16(1):109-39. doi: 10.1590/S0102-695X2006000100020.

22. Almeida ERd, Melo AM, Xavier H. Toxicological evaluation of the hydro-alcohol extract of the dry leaves of Peumus boldus and boldine in rats. Phytother Res. 2000;14(2):99-102. doi: 10.1002/(SICI)1099-1573(200003)14:2<99::AIDPTR600>3.0.CO;2-4.

23. Maduwanthi SDT, Marapana RAUJ. Total phenolics, flavonoids and antioxidant activity following simulated gastro-intestinal digestion and dialysis of banana (Musa acuminata, $A A B$ ) as affected by induced ripening agents. Food Chem 2021;339:127909. doi: 10.1016/j.foodchem.2020.127909.

24. Metropolitana-Xochimilco UA, Biológicos DDS, Hueso C. Activity of the main fatty acid components of the hexane leaf extract of Ricinus communis against Spodoptera frugiperda. Afr J Biotechnol. 2012;11(18):4274-8 et al.htm.

25. Schmidt J, Raith K, Boettcher C, Zenk MH. Analysis of benzylisoquinoline-type alkaloids by electrospray tandem mass spectrometry and atmospheric pressure photoionization. Eur J Mass Spectrom (Chichester). 2005;11(3):325-33. doi: 10.1255/ejms.745, PMID 16107747.

26. Salleh WMNHW, Mohammed NK, Hashim NA, Khamis S, Abed SA, Jibril S Chemical Constituents of Beilschmiedia penangiana. Chem Nat Compd. 2020;56(3):576-7. doi: 10.1007/s10600-020-03097-w.

27. Sultankhodzhaev MN, Abraeva ZC, Eshmatov ZM, Turgunov KK, Tashkhodzhaev B. Isotalatisidine hemihydrochloride sesquihydrate from Aconitum talassicum. Chem Nat Compd. 2015;51(3):601-3. doi: 10.1007/s10600-015-1362-0.

28. Chen CY, Kao CL, Kuo CE, Yeh HC, Song PL, Li HT. Secondary Metabolites of Annona cherimolia. Chem Nat Compd. 2021;57(1):141-4. doi: 10.1007/s10600021-03299-w.

29. Simirgiotis MJ, Schmeda-Hirschmann G. Direct identification of phenolic constituents in Boldo Folium (Peumus boldus Mol.) infusions by high-performance liquid chromatography with diode array detection and electrospray ionization tandem mass spectrometry. J Chromatogr A. 2010;1217(4):443-9. doi: 10.1016/j. chroma.2009.11.014, PMID 20022332.

30. Vinh LB, Nguyet NTM, Thanh CD, Huong TT, Tram LH, VanThong N, et al. Chemical constituents of Vietnamese mangrove Hibiscus tiliaceus with antioxidant and alpha-glucosidase inhibitory activity. Nat Prod Res. 2021;35(17):2899-904. doi: 10.1080/14786419.2019.1672065. PMID 31564138.

31. Yunusova SG, Yunusov MS, Fedorov NI. Seed lipids from Pulmonaria obscura. Chem Nat Compd. 2018;54(4):634-7. doi: 10.1007/s10600-018-2434-8.

32. Ibarra-Estrada E, Pacheco-Sánchez M, García-Mateos R, San Miguel-Chávez R, Ramírez-Valverde G, Soto-Hernández RM. Actividad antioxidante de alcaloides de Erythrina americana Miller. Rev Fitotec Mex 2011; 34 (4). Vol. 241.

33. Estevão MS, Carvalho LC, Ferreira LM, Fernandes E, Marques MMB. Analysis of the antioxidant activity of an indole library: cyclic voltammetry versus ROS scavenging activity. Tetrahedron Lett. 2011;52(1):101-6. doi: 10.1016/j.tetlet. 2010.10.172.

34. Wang $H$, Xu C, Zhang $X$, Zhang D, Jin F, Fan Y. Urease inhibition studies of six $\mathrm{Ni}(\mathrm{II}), \mathrm{Co}(\mathrm{II})$ and $\mathrm{Cu}(\mathrm{II})$ complexes with two sexidentate N2O4-donor bis-Schiff base ligands: an experimental and DFT computational study. J Inorg Biochem. 2020;204:110959. doi: 10.1016/j.jinorgbio.2019.110959. 


\section{GRAPHICAL ABSTRACT}

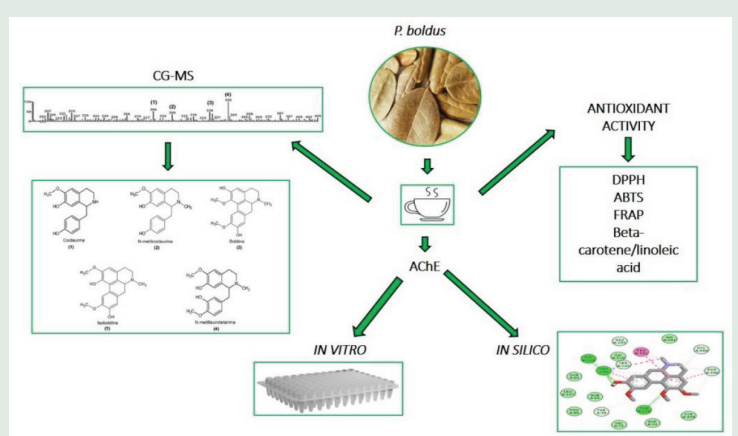

CG-MS: Gas Chromatography
coupled to the detector by Mass coupled to the
Spectrometry

DPPH: 1,1-diphenyl-2-picrylhydrazyl FRAP:ferric reducing antioxidant ABTS:2,2-azinobis-3power

\section{SUMMARY}

Medicinal plants have been traditionally used to treat all kinds of infirmities. Known in Brazil as boldo-do-chile, the species Peumus boldus Molina (Monimiaceae) is widely employed to relieve bowel discomfort. Increased gastrointestinal motility is associated to the action of the neurotransmitter acetylcholine (ACh), responsible for transmitting nerve impulses from one neuron to another for this purpose. To avoid excessive transmission of nerve impulses and its deleterious effects on biological functioning, our body produces an enzyme (acetylcholinesterase or AChE) that hydrolyzes ACh into choline (Ch), which is then reabsorbed by the first neuron to be reconverted to ACh during transmission of nerve impulses. AChE is involved in Alzheimer's Disease (AD) - a medical condition currently affecting about 35.6 million people worldwide - in that the latter causes degradation of neurons, thus decreasing the action of ACh. Although there is no cure to $\mathrm{AD}$, it can be effectively treated by means of AChEinhibiting drugs, which prevent ACh degradation. The traditional use of $P$. boldus suggests that the decoction of its leaves contains substances capable of inhibiting AChE, thereby promoting intestinal motility as more acetylcholine is available for inter-neuron communication. This study comprises the procedures for the preparation of the aqueous extract of $P$. boldus leaves (EAFPb), identification of its constituents by means of electrospray ionization mass spectrometry (ESI-MS), assessment of antioxidant activity (DPPH, ABTS, FRAP, and oxidation inhibition of the $\beta$-carotene/linoleic acid system), quantification of total phenols, and in silico determination of AChE inhibitory activity through molecular docking assays. Mass spectrometry identified the presence of the alkaloids isoboldine, boldine, clocaurin, laurotetanin, $N$-methylaurotetanin, reticulin, and $\mathrm{N}$-methylcoclaurine in EAFPb. The in silico prediction assay indicated that the alkaloid N-methyllaurotetanin constitutes the best acetylcholinesterase enzyme inhibition ligand, with energy of -10.1 $\mathrm{kcal} / \mathrm{mol}$. The extract was shown to be potentially active in all analyses for antioxidant activity. The results obtained in this study suggests that $\mathrm{EAFPb}$ contains chemical constituents with potential for treating AD.

Cite this article: Silva BYK, Lopes ASN, Maia PJS, Mar JM, Silva LS, Sanches EA, Corrêa GM, Bezerra JA, Carmo DFM. Chemical and Biological Evaluation of the Aqueous Extract of Peumus boldus Molina (Monimiaceae) Leaves. Extract on Pre-diabetic Subjects. Pharmacog Res. 2022;14(1):45-52. 